\title{
UM OLHAR SOBRE OS AJUSTAMENTOS PRIMÁRIOS E SECUNDÁRIOS NUM CONTEXTO DE EDUCAÇÃO INFANTIL
}

Márcia Buss-Simão*

RESUMO: As reflexões tecidas nesse texto são um recorte de uma pesquisa de doutorado já concluída em que a pesquisa de campo foi conduzida em uma instituição pública de educação infantil da rede municipal de Florianópolis. Para trazer uma descrição a partir da perspectiva das crianças foram utilizados procedimentos metodológicos provenientes da etnografia como registros escritos, fotográficos e fílmicos. Nos limites desse artigo serão desenvolvidas reflexões e análises que se referem a um recorte - momento do sono - dentro da rotina cotidiana vivida pelas crianças nessa instituição de educação infantil. Com as reflexões e análises se objetiva dar visibilidade tanto aos ajustamentos primários como aos ajustamentos secundários, no confronto dos espaços-tempos dos adultos e dos espaços-tempos das crianças. A intenção é analisar até que ponto as crianças se conformam e de que modo subvertem aquela organização dos espaços e tempos institucionais.

Palavras-chave: Educação Infantil; Cotidiano; Espaço e Tempo; Ajustamentos Primários e Secundários.

\section{A LOOK AT THE PRIMARY AND SECONDARY ADJUSTMENTS IN THE CONTEXT OF EARLY CHILDHOOD EDUCATION}

ABSTRACT: The reflections presented in this paper were excerpted from a doctoral research carried out in a public Early Childhood Education school in the municipality of Florianópolis state of Santa Catarina Methodological procedures from the ethnography, such as written records, photographs and film were used to make a description from the perspective of the children. In this paper, we develop ideas and analyses that refer to a clipping - the sleep time - in the daily life experienced by children in this institution of education. The reflections and analyses aim to give visibility to primary adjustments and secondary adjustments in the confrontation of the space-time of adults and children. The intention is to analyze, to what extent, children conform and how they subvert to the organization of institutional space and time.

Keywords: Early Childhood Education; Daily Life; Space and Time; Primary and Secondary Adjustments.

\footnotetext{
*Pós-Doutoranda em Educação na Universidade Federal de Santa Catarina e Pesquisadora do Núcleo de Estudos e Pesquisas da Educação na Pequena Infância (NUPEIN). Email: marciabsimao@bol.com.br
} 


\section{CONTEXTUALIZANDO O CAMPO E A TEMÁTICA}

As reflexões tecidas neste texto são um recorte de uma pesquisa de doutorado concluída no ano de 2012. A fim de trazer uma descrição a partir da perspectiva das crianças utilizei procedimentos metodológicos provenientes da etnografia, lançando mão de registros escritos, fotográficos e fílmicos ${ }^{1}$. A pesquisa de campo foi realizada de 3 a 4 vezes por semana, ao longo de nove meses no ano de 2009, em uma instituição pública de educação infantil da rede municipal de Florianópolis, localizada em zona urbana que atende crianças de 0 a 6 anos de idade em período integral.

O grupo pesquisado era composto por 15 crianças com idade entre 2 e 3 anos, sendo 12 meninas e 3 meninos. A grande maioria das crianças era procedente de família nuclear, sendo que metade do grupo era filho único, a outra metade tinha um ou dois irmãos. A grande maioria, do total de crianças do grupo pesquisado, enfrentava dificuldades em sua condição social e econômica.

A utilização de procedimentos provenientes da etnografia objetivou uma aproximação a um ponto de vista das crianças, pois se concebe que esses procedimentos permitem uma participação mais direta com e das crianças na geração dos $\operatorname{dados}^{2}$ a fim de conseguir reunir informações sobre os modos como elas manifestam e percebem o cotidiano de uma instituição de educação infantil nas relações que estabelecem com os adultos e com seus pares.

No caso desta pesquisa, a realidade concreta à qual se dirigiu o olhar foi a estrutura social de uma instituição de educação infantil. Compreendo que essa estrutura social - instituição de educação infantil - é imposta pelos adultos, sendo, portanto, um contexto privilegiado para investigar como as crianças lidam com essas estruturas e como elas se manifestam nessas relações de poder com os adultos e com as outras crianças. Com base em Ferreira $(2002,2004)$ concebo essa estrutura social adulta dotada de duas propriedades, ou seja, primeiro como resultado de uma construção sócio-histórica que se destina à socialização das crianças, e segundo, como resultado da presença do adulto-professora, a qual se torna o elo que representa e assegura que essa estrutura social funcione por meio dos arranjos espaciais e temporais na organização e planejamento do cotidiano para e com as crianças. No entanto, importa destacar que o sentido dessa 
ordem institucional adulta não é apenas redutível ao nível desses arranjos espaciais e temporais na organização e planejamento do cotidiano para as crianças, mas envolve um quadro mais amplo, ou seja, da ordem e das relações intergeracionais, que permite apreender o sistema de princípios, regras e valores que os fundam.

Embora o adulto-professora ocupe uma posição central nessa estrutura social, sua relevância nesse estudo e também nesse artigo é, no entanto, periférica e relativamente indireta, não pretendo me deter nas suas competências pedagógicas nem nas suas concepções de crianças e seus pontos de vista em relação às crianças. O que interessa considerar nesse estudo é que, dada essa ordem institucional adulta, as crianças, ao participarem dessa estrutura - instituição de educação infantil - por meio de ações sociais organizadas e regulares que permitem a sua reprodução no espaço e no tempo, passam a se integrar tanto na ordem institucional adulta, bem como numa ordem emergente criada por elas: ordem social infantil instituinte ou emergente, como define Ferreira (2002, 2004).

As crianças, ao instituírem essa ordem social emergente, criam uma realidade alternativa à ordem institucional adulta, tendo como referência valores e regras sociais delas próprias, revelando que elas não se limitam a reproduzir o mundo dos adultos. Pelo contrário,

[...] o reconstroem e ressignificam através de múltiplas e complexas interações com os pares, permite mostrá-las não só como autoras de suas próprias infâncias, mas também como atores sociais com interesses e modos de pensar, agir e sentir específicos e comuns, capazes de gerar relações e conteúdos de relação, sentido de segurança e de comunidade que estão na sua gênese como grupo social. (FERREIRA, 2004, p. 58).

Objetivando olhar o cotidiano de uma instituição de educação infantil, a partir da perspectiva das crianças, com a finalidade de compreender a emergência e afirmação de uma ordem social emergente, é preciso deslocar o ângulo de análise de "cima para baixo", é preciso: "[...] a identificação e análise da simultânea e recíproca construção social de três processos centrais: o da cultura das crianças, o da sua organização como grupo social de 'pares' e o da(s) sua(s) ordem(ns) sociai(s).” (FERREIRA, 2004, p. 58-59).

Ao se encontrarem regular e rotineiramente no mesmo contexto institucional, e ao realizarem cotidianamente atividades conjuntas e ordenadas que satisfazem expectativas comuns e recíprocas, as crianças geram, na 
sua prática e nas suas relações, uma ordem social emergente, a qual é socialmente convencionada por elas próprias regulando e organizando as ações individuais e coletivas desse grupo. Tais ações não fazem sentido fora do seu contexto, ou seja, não têm sentido isoladamente, elas só fazem sentido se interpretadas contextualmente. Elas só se tornam acontecimentos sociais se negociadas e interpretadas ou reinterpretadas com os outros, por meio de suas interações sociais. Identificar e compreender essa ordem social emergente tem sido também um desafio para os pesquisadores, pois é preciso que se "mergulhe" nessa ordem social que é construída pelas crianças para que se possa legitimá-la e para que seja possível uma aproximação à perspectiva delas e dos seus modos de se socializarem. Além disso, como afirma Danby (2005, p. 177): "Pelo reconhecimento das ordens sociais das crianças, ordens sociais dos adultos podem ser também identificadas"

\section{AJUSTAMENTOS PRIMÁRIOS E AJUSTAMENTOS SECUNDÁRIOS}

O objetivo central aqui é vislumbrar como as crianças, ao se confrontarem com a organização dos espaços-tempos institucionais adultos, fazem uso desse tempo e desse espaço e como os transformam. A intenção é analisar até que ponto as crianças se conformam e, de que modo, subvertem aquela organização dos espaços e tempos institucionais. É tentar perceber e identificar quais outras geografias as crianças criam nesse tempo e espaço com a intenção de uma aproximação para se conhecer quais expressões, ou quais sentidos revestem essas ações sociais nas suas relações com as outras crianças e com os adultos.

Para evidenciar as ações sociais ${ }^{4}$ das crianças em situações ordinárias de atividade concreta no cotidiano da instituição de educação infantil, procuro apoiar-me em referenciais teóricos dos estudos sociais da infância, ${ }^{5}$ os quais fundamentam a pesquisa que está na base do presente artigo. Com base nesse referencial teórico se concebem as crianças como atores sociais, na busca por compreender como elas enfrentam os entendimentos que os adultos manifestam sobre as crianças e a infância, bem como também se elas entendem os adultos e ao mesmo tempo a si próprias. Com isso, pretendendo chegar a uma compreensão das interrelações entre ação e estrutura nesse contexto. 
Para tanto, passa a ser imprescindível não descontextualizar a ação social dos enquadramentos estruturais em que acontece, sendo que a ação social não acontece suspensa do social e contém em si própria as propriedades duais, que tanto lhe colocam limites como a convidam a desafiá-los. Nessa direção Ferreira (2004, p. 26) indica que a “[...] ação social pode assumir sentidos estratégicos de resistência, transformação e apropriação, também recobre, e não com menos importância, os de adaptação e conformidade [...]", podendo, com isso, participar da reprodução social de preconceitos, esteriótipos e idealizações conservadoras que asseguram a manutenção das desigualdades sociais.

Objetivando não cair numa compreensão de ação social baseada num determinismo da estrutura ou na exaltação voluntarista e individual dos atores sociais, a reprodução interpretativa (CORSARO, 2002, 2005, 2009) se constitui um conceito útil para compreender os processos de reprodução, mas também de produção social. O conceito de reprodução interpretativa institui um nexo entre o mundo adulto e o mundo infantil, em que as crianças reproduzem interpretativamente o mundo adulto. $\mathrm{O}$ termo reprodução procura captar a ideia de que as crianças são constrangidas e afetadas pelas estruturas sociais e pelas culturas já existentes, ou seja, pela reprodução social nas sociedades das quais participam, e que, pela sua participação efetiva, também contribuem recíproca e ativamente para a produção e mudança social e cultural do mundo adulto.

Por outro lado, o termo interpretativo procura dar relevo aos aspectos inovadores, criativos e transformadores das perspectivas e participações das crianças nas relações sociais. Esse termo salienta apropriações seletivas, reflexivas e críticas que as crianças são capazes de fazer do mundo adulto quando, em um processo de interpretação, o fazem de acordo com seus interesses, necessidades e preocupações como crianças. Nesse processo, as crianças desenvolvem uma troca e uma negociação de significados e intencionalidades, as quais passam a ser, ao longo do tempo, partilhadas subjetiva e coletivamente por meio das relações e interações sociais, o que poderia ser definido como a elaboração de uma ordem social infantil.

Procurar compreender, num contexto de educação infantil, as crianças como atores sociais competentes é, ao mesmo tempo, tornar evidente os ajustamentos primários à organização espaço-tempo criada pelo adulto-professora, bem como evidenciar os ajustamentos secundários que as próprias crianças instituem nesse espaço-tempo. Com base em Goffman 
(1961), ao analisar instituições totais, é possível afirmar que, também nas instituições de educação infantil, tanto os ajustamentos primários como os ajustamentos secundários são definições sociais que coexistem nessa instituição. Ao coexistirem, constituem-se em modos pelos quais os participantes da instituição, por um lado, se integram à instituição ou, por outro lado, se distanciam das suas regras, dos seus objetivos ou dos valores dessa organização, dando forma a uma infinidade de possibilidades de ação.

Por um lado, as crianças aderem a essa organização dos espaços e tempos pensados e efetivados pela professora e pelas auxiliares; com isso, elas aderem também a uma ordem institucional adulta contribuindo com sua integração como crianças "membros da instituição de educação infantil" por meio dos ajustamentos primários, ou seja, como apresenta Goffman (1961, p. 159) quando as crianças contribuem

[...] cooperativamente com a atividade exigida por uma organização, e sob as condições exigidas - em nossa sociedade com o apoio de padrões institucionalizados de bem-estar, com o impulso dado por incentivos e valores conjuntos, e com as ameaças de penalidades indicadas.

Por outro lado, quando as crianças empregam " [...] meios ilícitos, ou conseguem fins não autorizados, ou ambas as coisas, de forma a escapar daquilo que a organização supõe que deve fazer e obter e, portanto, daquilo que deve ser [...]" (GOFFMAN, 1961, p. 160), elas lançam mão dos ajustamentos secundários, os quais, também podem ser definidos como um submundo da instituição. Nesse submundo, os ajustamentos secundários, pelo fato de serem ações "proibidas", propiciam um sentido de autonomia e autenticidade frente aos constrangimentos da instituição, sendo também capazes de gerar, entre as crianças, um conjunto de saberes e fazeres que as envolvem em ações cooperativas entre elas em busca de seus interesses. No entanto, como alerta Goffman (1961, p. 165), isso não significa que as crianças se comportem como um grupo homogêneo, pois, "[...] o que é ajustamento primário para uma categoria de participante pode ser ajustamento secundário para outra”. Esse fato não invalida a ideia central de que, por meio dos ajustamentos secundários, as crianças têm possibilidades reais de gerarem atividades ou organizações novas e qualitativamente diferentes, como também atividades e organizações iguais ou muito semelhantes, mas percebidas por elas como distintas, pois fazem parte de sua estruturação como um grupo, com dada cultura, que procura 
se afirmar perante os enquadramentos primários definidos pela ordem institucional adulta.

Segundo Goffman (1961), os ajustamentos secundários podem se apresentar de variadas formas, desde substituições no sistema em que os "[...] participantes utilizam os artefatos disponíveis de uma maneira e para um fim que não são oficialmente destinados, e assim modificam as condições de vida programadas para eles [...]” (GOFFMAN, 1961, p. 173). Os ajustamentos secundários podem também se revestir do que Goffman (1961) define como trabalhar o sistema, ou seja, quando os participantes agem num sentido de explorar o conhecimento que têm da organização da instituição, no qual "[...] o espírito da atividade legítima da instituição pode ser mantido, mas é realizado numa extensão não prevista; [...] a exploração de uma rotina completa de atividade oficial para fins particulares" (GOFFMAN, 1961, p. 175). Ainda conforme esse autor, "[...] a fim de explorar eficientemente o sistema é preciso conhecê-lo profundamente" (GOFFMAN, 1961, p. 177) para, a partir das vulnerabilidades da instituição, poder legitimar práticas. Tendo em conta que as instituições revelam suas fragilidades por meio dos ajustamentos secundários, elas podem também, para manter o controle e a soberania, legitimar seletivamente algumas dessas práticas, sobretudo as mais visíveis ou as que mais se desenvolveram. Desse modo, um ajustamento secundário pode tornar-se um ajustamento primário legitimado institucionalmente.

\section{QUADRO PRIMÁRIO DEFINIDO PELO ADULTO-PROFESSORA}

Ao acompanhar durante nove meses a rotina cotidiana desse grupo de crianças na instituição, é possível verificar que há um padrão de temporalidade que regula, coordena e controla os encontros sociais nos espaços e organiza os comportamentos e orienta as ações, pois o recorte do tempo se dá acompanhado do recorte das atividades, como é possível ver no esquema da organização da rotina: das 7 h até às $8 \mathrm{~h}$ chegada; entre $8 \mathrm{~h}$ e 8 h30 café da manhã; das $8 \mathrm{~h} 30$ às $9 \mathrm{~h} 30$ roda e a atividade pedagógica; das $9 \mathrm{~h} 30$ às $10 \mathrm{~h} 30$ parque $^{6}$ ou atividade livre; entre $10 \mathrm{~h} 40$ e $11 \mathrm{~h}$ almoço; das $11 \mathrm{~h} 30$ às $13 \mathrm{~h}$ horário do sono; entre $13 \mathrm{~h}$ e $13 \mathrm{~h} 30$ lanche da tarde; das $14 \mathrm{~h}$ às $15 \mathrm{~h} 30$ parque ou atividade livre; entre $15 \mathrm{~h} 40$ e $16 \mathrm{~h}$ jantar; entre 
$16 \mathrm{~h} 30$ e 19h, despedida, sendo esse horário bem flexível, pois, enquanto algumas crianças vão embora por volta das $17 \mathrm{~h}$ outras ainda permanecem na instituição até as $19 \mathrm{~h}$.

Com o objetivo de dar visibilidade tanto aos ajustamentos primários como aos ajustamentos secundários, no confronto dos espaços-tempos dos adultos e dos espaços-tempos das crianças, é importante compreender que o funcionamento da organização desse espaço efetivado pela professora continha regras e restrições quanto ao uso desses espaços e dos materiais que estavam atrelados ao tempo da rotina institucional. $\mathrm{Ou}$ seja, não havia, necessariamente, uma restrição ao uso dos materiais, mas havia uma restrição de acesso ao uso, o qual era determinado pela rotina institucional.

Nessa configuração da rotina cotidiana, é possível também identificar duas grandes temporalidades, as quais categorizo a partir de indicações de Ferreira (2002, 2004): os tempos do adulto-professora e os tempos das crianças. Os tempos do adulto-professora se caracterizam, sobretudo, pela sua iniciativa explícita e implicam sua relação formal com as crianças em que ela tem um papel central e ativo. Essa sua atuação é tanto direta, ou seja, nos momentos coletivos com as crianças ao definir, determinar e regular os horários de refeição, higiene, sono, roda e atividade pedagógica, parque, entradas e saídas, e também é uma atuação no contínuo desses momentos em que ela, individualmente, ou em pequenos grupos, media a efetivação dessas atividades.

Já os tempos das crianças que, no entanto, são também definidos, determinados, gerenciados, fracionados e recortados pelos adultos e pela rotina da instituição, podem ser visualizados no que se denomina extraoficialmente: horários do parque ou tempos do brincar ou ainda atividades livres ${ }^{7}$. Ou seja, quando explicitamente é dito às crianças que podem utilizar o espaço e os materiais da forma que quiserem bem como podem interagir com quem quiserem. Nesse tempo das crianças, elas é que têm o papel ativo e central na tomada de decisão e na condução das ações, na administração, manutenção e permanência ${ }^{8}$ das e nas atividades e interações. São as crianças que decidem onde querem ir e o que querem fazer num determinado lugar e tempo, exercendo poderes plenos na recriação desse contexto. Nesse tempo instituído pelas crianças, a professora e a auxiliar se colocam na retaguarda e assumem um papel subsidiário, ou 
seja, intervindo somente quando solicitadas pelas crianças para auxiliar em alguma brincadeira ou na resolução e mediação de conflitos, ou ainda para determinar o fim do tempo do brincar em função da rotina institucional.

\section{AJUSTAMENTOS PRIMÁRIOS E AJUSTAMENTOS SECUNDÁRIOS: CENAS NA ROTINA DO SONO}

Diariamente, de acordo com o planejamento e definição de uma ordem institucional, entre $11 \mathrm{~h} 30$ e $13 \mathrm{~h}$ acontece o horário do sono. Para esse horário, o espaço da sala é arranjado para que as crianças possam dormir na própria sala, sendo as mesas afastadas e colchões são distribuídos por quase toda a sala, com maior concentração na parede da janela. As crianças que fizeram sua higiene já devem se deitar enquanto aguardam as demais. Nesse momento, enquanto aguardam as demais crianças, é quando elas criam estratégias para explorar esse espaço para outros fins que não o planejado, como é possível ver nas fotos a seguir.

\section{Sequência de fotos 1}

\section{Dançar e pular sobre os colchões ou dançar e correr sobre os}

colchões ou ainda brincar nos colchões.
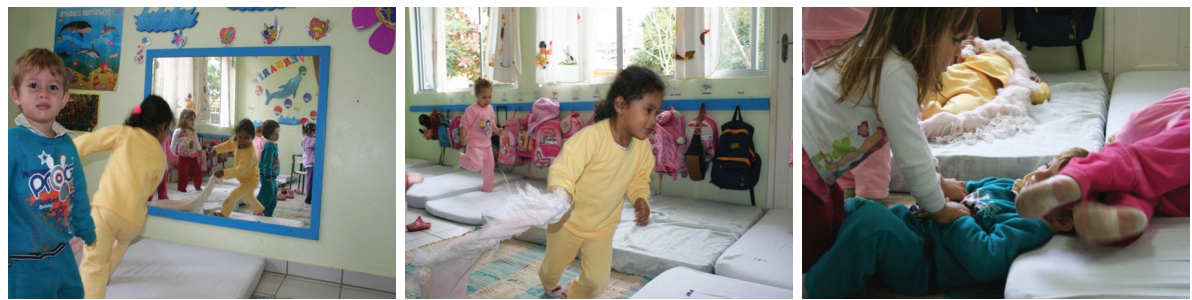

Fonte: autora, em 23/6/2009.

\section{Sequência de fotos 2}

Brincar nos colchões, conversar nos colchões e rolar juntos nos colchões.
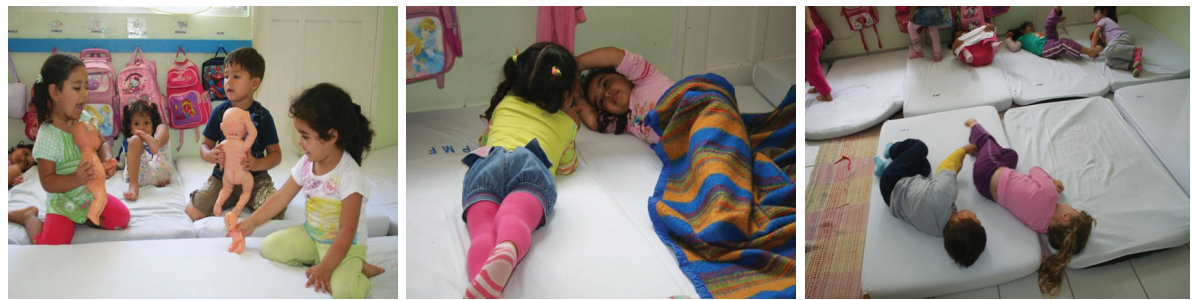

Fotos: da autora, em 10/11/2009, 19/10/2009 e 27/10/2009. 
As crianças, com o conhecimento de que nesse momento os dois adultos estão "ausentes" e envolvidos com a higiene das demais crianças no banheiro que fica ao lado da sala, por meio de ajustamentos secundários, compõem diversos e diferentes usos para os colchões preparados para a hora do sono. A partir desses ajustamentos secundários as crianças criam formas estratégicas de se afastar, nem que por alguns minutos, da conduta exigida para esse momento pela ordem institucional adulta. Por outro lado, também os adultos estão cientes dessas ações das crianças e se mostram não totalmente inflexíveis ou irredutíveis, mas colaboram, por alguns instantes, com esse ajustamento secundário fazendo "vista grossa" para continuarem sua função com a higiene das demais crianças, como indica Goffman (1961), permitindo e legitimando, em parte, um ajustamento secundário.

Assim que todas as crianças terminam de fazer sua higiene, os adultos assumem e impõem a obrigatoriedade do ajustamento primário para o tempo de dormir. Definidor para esse tempo de dormir é que as crianças fiquem deitadas sobre os colchões e sem conversar para, aos poucos, adormecerem. Para que esse processo do adormecer aconteça de forma mais eficaz, a professora e a auxiliar utilizam uma estratégia para conter/ embalar as crianças. A estratégia consiste em sentar entre duas crianças e conter/embalar, ao mesmo tempo, duas crianças de cada vez, dando palmadinhas no seu bumbum. À medida que essas crianças adormecem, cada profissional contém/embala mais outras duas crianças, até que todas estejam adormecidas. A escolha de quais crianças conter/embalar não é aleatória, há uma seleção de quais crianças devem ser contidas/embaladas primeiro. Definidor para essa escolha é o entendimento e a compreensão que tanto a professora como a auxiliar têm do grupo de crianças, selecionando aquelas que normalmente são as mais "agitadoras". Enquanto ambas contêm/embalam duas crianças, ao mesmo tempo, as demais crianças devem permanecer deitadas e se aquietar para dormir, sendo constante, por parte das profissionais, o uso do recurso da afirmação: "Quem não deitar e ficar quietinho eu vou embalar"' objetivando, com isso, que as demais crianças se mantenham deitadas. 


\section{Sequência de fotos 3}

Professora embala Letícia e Nicole, depois Manu e Larissa; Léo e Amanda, adormecidos; e, no espelho, auxiliar embala Ana Laura e Bibi.
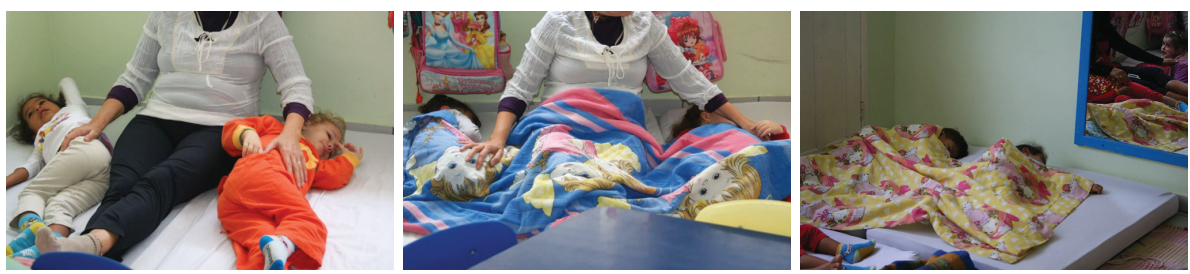

Fotos: da autora, em 8/5/2009.

No entanto, permanecer deitadas, sem se movimentar, sem falar, sem poder fazer nada, para em seguida adormecer, parece exigir um controle e uma contenção grande das crianças, o que nem sempre é alcançado por todas elas, como é possível observar no excerto que segue:

Isadora $^{10} e$ Larissa são as que mais resistem para dormir, juntamente com Tainá. Larissa e Isadora estão lado a lado no colchão e se comunicam sem palavras, somente por meio de gestos. Isadora com a mão estendida pede o bico da Larissa e essa o entrega para Isadora. Isadora observa o bico e faz. menção de colocar na boca e a auxiliar percebe a intenção e a repreende. Com isso, Isadora imediatamente devolve o bico para Larissa.

Isadora argumenta dizendo em voz baixa: "Ela me deu".

Depois disso, Isadora e Larissa continuam uma conversa com gestos, procurando se tocar com as mãos. Criam uma brincadeira de se arrastar no colchão como "minhocas" e nisso Tainá observa e quer se juntar a elas também, mas a auxiliar se aproxima e senta perto das duas para que durmam e não brinquem. Observo que Tainá está com a atenção a um ponto preto no colchão, toca esse ponto preto, observa e depois observa o espelho que está bem próximo a ela. Por volta das 11 h42 as primeiras crianças que foram embaladas já adormeceram. Larissa e Isadora continuam sua conversa sem falas: tapam os olhos com as mãos e depois se olham e sorriem (Registro notas de campo do dia 30/3/2009).

O momento do sono, instituído pela ordem institucional adulta que prevê, em sua organização, um momento para o descanso, não prevê, no entanto, que seja um momento em que as crianças possam descansar sem, necessariamente, dormir. Como no excerto acima, Larissa e Isadora utilizam uma comunicação corporal e gestual como meio de contrapor a exigência do silêncio, a qual precisa também ser silenciada pelos adultos. Como destaca Batista (1998, p. 131), os adultos, no momento do sono, têm 
o papel de "[...] seguir os preceitos organizacionais da rotina, ou seja, buscar manter o silêncio e a ordem necessária para não contaminar o silêncio e a ordem das outras turmas [...]", numa tentativa de assegurar, a todo custo, os ajustamentos primários definidos para toda a instituição.

As crianças, por sua vez, mobilizam um repertório de competências sociais, relacionais, práticas, corporais e discursivas, em que, por um lado, legitimam a ordem institucional adulta perante seus pares consolidando os ajustamentos primários, por outro lado, confrontam essa mesma ordem institucional adulta trazendo novos elementos e outras possibilidades.

\begin{abstract}
Amanda está deitada no colchão e pega um bebê. Nisso Willian se aproxima e diæ:
Willian: Amanda, não pega, guarda! Não pode dormir com brinquedo!

No entanto, os dois levantam dos colchões e ficam mexendo em objetos sobre a mesa, mas logo recebem a indicação de que devem dormir e se deitam rapidamente no colchão.
\end{abstract}

William: quer dormir comigo? [pergunta para Amanda].

Willian e Amanda estão juntos no colchão, se olham e sorriem. Willian faz carinho no rosto da Amanda e tira a trança que caiu sobre seus olhos e rosto. A professora dá indicação que o Willian deve mudar de lugar para dormir, pois está conversando muito com Amanda e ele então justifica:

Willian: a Amanda vai dormir comigo! A Amanda é minha amiga!

Professora: eu sei que a Amanda é tua amiga.

Com esse argumento a professora deixa que eles permaneçam juntos.

Willian levanta a camiseta e mostra sua barriga:

Willian: quer ver minha barriga?

Amanda olha para a barriga e em seguida dá um tapa carinhoso em sua barriga. Continuam a conversar, agora sobre as cores dos prendedores das tranças da Amanda. A auxiliar pede que Amanda vá deitar em outro lugar para que durmam e parem de brincar (Registro notas de campo do dia 24/8/2009).

No excerto acima Willian, por um lado, consolida a regra de uma ordem institucional adulta de que não pode dormir com brinquedos, mas por outro lado subverte essa mesma ordem ao acompanhar Amanda na busca de brinquedos sobre a mesa. $\mathrm{Na}$ sequência, estabelece uma aproximação e um diálogo verbal, mas sobretudo corporal com Amanda, confrontando, mais uma vez, a determinação da ordem adulta para esse momento do sono. Assim como no uso empregado ao espaço organizado com os colchões para 
o horário do sono, aqui também, a partir de ajustamentos secundários as crianças criam formas estratégicas de se afastar da conduta exigida para esse momento pela ordem institucional adulta e, por outro lado, os adultos cientes dessas ações das crianças por alguns instantes colaboram e permitem, em parte, o ajustamento secundário.

\section{HORA DO SONO QUE SE ESTENDE PARA OUTROS TEMPOS E ESPACְOS: AMANDA: “ME FAZ DORMIR?" MÁRCIA: “COMO É FAZER DORMIR?"}

Para além desses ajustamentos secundários empregados pelas crianças no momento do sono, a estratégia utilizada pelos adultos para conter/embalar as crianças dando palmadinhas no seu bumbum se tornou emblemática e representativa da ordem institucional adulta, pois passou a ser estendida pelas crianças para outros tempos e espaços.

Desde o primeiro dia da pesquisa de campo, no horário do parque ou de atividade livre, observei algumas crianças que estavam em cima do escorregador e brincavam, do que passei a denominar de: "fazer dormir". A brincadeira consistia em uma ou mais crianças embalarem outras crianças, dando palmadinhas no bumbum, sendo que elas se revezavam entre o papel de dormir e o de fazer dormir.

No parque observo um grupo de crianças que estão sobre o escorregador, são: Isadora, Helena, Leticia, Emanuele, Willian e Bianca. Observo que brincam de "fazer dormir": Bianca e Helena estão deitadas de brucos sobre a base de madeira do escorregador entre a Isadora, que sentada as embala. Helena faz menção de se levantar, mas Isadora diz:

Isadora: deita Helena!

Helena pede: bate na minha bunda.

Isadora está sentada entre elas e bate - embala - com as mãos no bumbum de cada uma delas, enquanto embala faz o som: xixixxixixixix

Ao mesmo tempo Emanuele embala e bate no bumbum de Bianca e William.

Helena se levanta e diz: Papai vai trabalhar!

Com a saida de Helena, Isadora passa a bater no bumbum de Willian e Bianca sendo que ao mesmo tempo murmura:

Isadora: xixixixixix e em seguida diz: Tá na hora de acordar! (Registro Notas de Campo do dia 30/4/2009) 


\section{Foto de vídeo 4}

Nicole embala Léo.

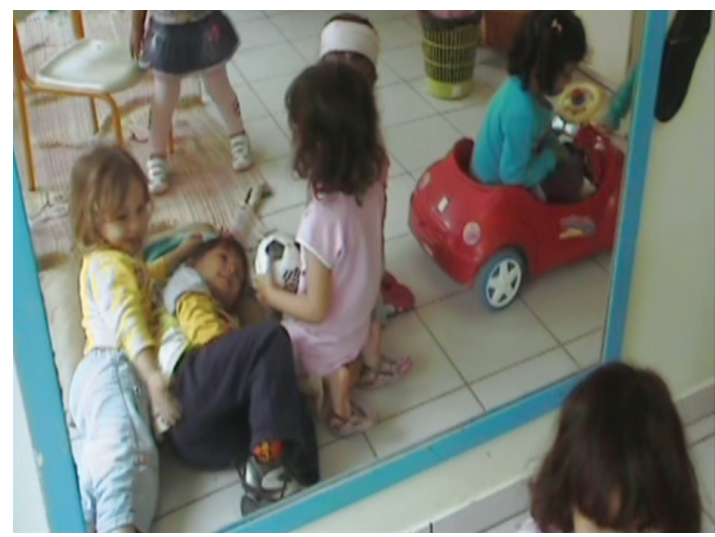

Fonte: da autora, em 15/10/2009.

\section{Foto de vídeo 5}

Isa embala Helena.

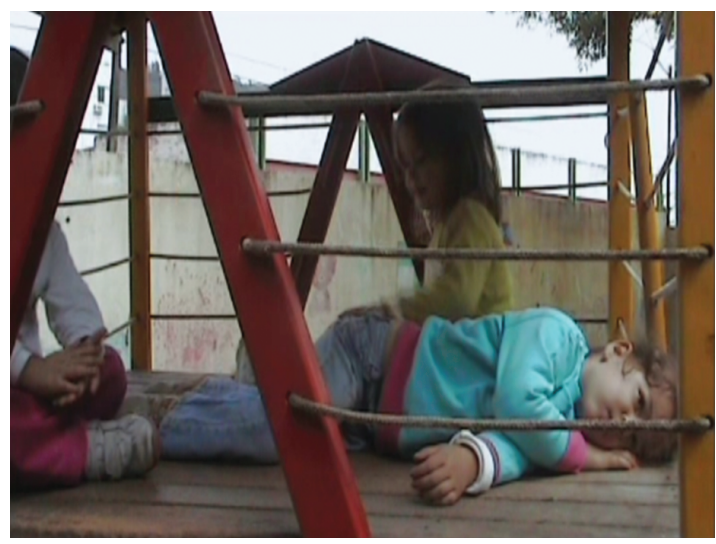

Fonte: da autora, em 14/10/2009.

Episódios semelhantes foram observados recorrentemente, como nas cenas acima, recortadas de vídeos realizados em outubro, sendo que havia pequenas variações como quando as crianças embalavam seus bebês/bonecas para adormecerem. No entanto, mais recorrentemente, eram as próprias crianças que eram embaladas com palmadinhas em seus bumbuns nas brincadeiras vividas entre elas. Nesses episódios observados, as palmadinhas continham, ao mesmo tempo, duas finalidades ou "faces": conter e embalar. No episódio acima, essas duas finalidades se tornam evidentes, 
por um lado, quando Helena faz menção de se levantar e Isadora lhe diz: "deita Helena!". Na sequência, Helena solicita ser embalada novamente: "bate na minha bunda". O pedido de Helena parece revelar que ela deseja ser embalada mesmo após a reprimenda de Isadora.

No episódio a seguir, que ao contrário do anterior acontece na sala, novamente a brincadeira envolve o "fazer dormir", estando presentes também essas duas finalidades ou "faces" nas palmadinhas:

Na sala, Nicole e Letícia juntam cadeiras para montar uma cama. Em seguida Isadora que está ao telefone na mesa ao lado se junta a elas e a pedido da Nicole traz sua cadeira. Léo se aproxima e observa e fala ao celular se olhando no espelho. Willian entra em cena, sobe na cadeira e Nicole entra em conflito com ele, depois da mediação da auxiliar, Willian brinca com Nicole, porém mantém-se um certo conflito entre eles. Em certo momento ele assume o papel de pai da Nicole que está deitada e faz carinho nela. Nessa brincadeira Isadora é a mãe. Na sequência Willian faz a filha dormir dando palmadinhas em suas costas e bumbum. Quando Nicole se levanta ele fala em tom de ordem:

Willian: deita bebê!

Willian percebe que estou filmando e fala: Eu tô fazendo ela naná...

Logo em seguida:

Nicole pede: quero dedera... quero dedera...

Willian dá fortes palmadinhas em seu bumbum, quanto mais Nicole pede mais ele aumenta a força das palmadinhas. Em seguida ele aproxima seu rosto do rosto da Nicole para ouvir o que ela está pedindo.

Willian: você quer mamadeira para mamá?

Nicole: quero dedera.

Willian: na teta?

Nicole: não. Mamadeira.

Willian levanta e fica em pé na cadeira e chama Isadora que está do outro lado da sala: Maaaaaeeeee! Maaaaaeeee! Vem! Vem aqui para casa.

Isadora fala algo em voz baixa e não consigo identificar.

Willian fala: Vem, ela qué mamá.

Nicole que estava deitada se senta e corrige: não, quero mamadeira.

Willian: deita filha, deita filha.

Mas Nicole se levanta e caminha sobre as cadeiras, Willian faz o mesmo e logo Nicole volta a deitar, seguindo a indicação de Willian e com isso dá sequência à brincadeira de fazer dormir. Em seguida todas as crianças são chamadas para ir ao parque e a brincadeira se desfaz (Registro em vídeo do dia 31/8/2009). 


\section{Foto de vídeo 6}

Willian embala Nicole e Léo observa.

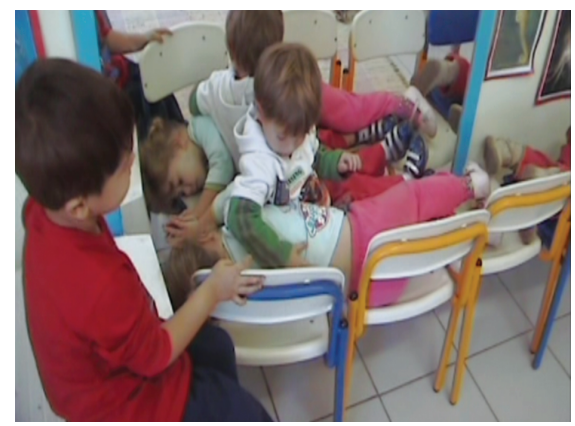

Fonte: da autora, em 31/8/2009.

\section{Foto de vídeo 7}

\section{Willian embala Nicole e Manu dorme.}

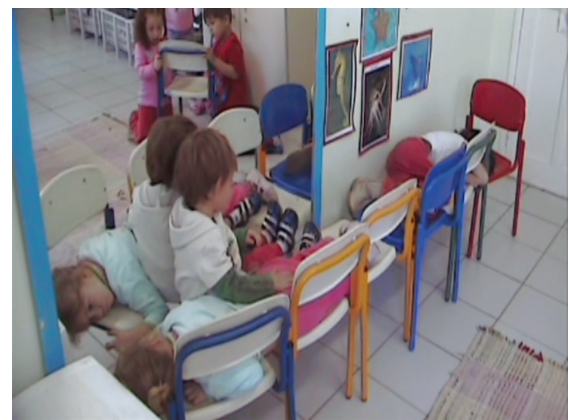

Fonte: da autora, em 31/8/2009.

No episódio descrito, além da recorrência da brincadeira do "fazer dormir”, chama atenção essa organização do espaço para a brincadeira. As crianças reorganizam as cadeiras que, na brincadeira, servem de cama. Percebe-se que o uso das palmadinhas dadas pelo "pai" Willian em sua "filha" Nicole também apresenta as duas finalidades ou "faces": uma forma de embalar e, ao mesmo tempo, um meio de conter. A "face" da contenção pode ser evidenciada quando Nicole faz algum movimento para levantar e Willian responde batendo mais forte no seu bumbum acompanhado do pedido/ordem: "deita bebêe?"; "deita filha?" Já a "face" do embalar pode ser evidenciada quando Willian esclarece: "eu tô faz̧endo ela nanâ". 
Inicialmente, observava as cenas do "fazer dormir" somente nos tempos instituídos pelo adulto-professora como integrantes dos designados tempos das crianças, momentos em que as crianças possuem maior autonomia relativa para afirmar as suas culturas infantis, ou seja, momentos do brincar em sala e no parque, pois, nos primeiro dias da pesquisa de campo no período matutino, permaneci em campo somente até o horário de almoço do grupo ${ }^{11}$. Ao permanecer até mais tarde na instituição e acompanhar a rotina do horário do sono, a qual acontecia logo depois do almoço, percebi que as profissionais utilizavam essa estratégia para acalmar as crianças para que adormecessem e, também, como forma de conter aquelas que queriam levantar ou não dormir.

A análise e compreensão do momento do sono como um ajustamento primário, determinado pela ordem institucional adulta, parece indicar que há, na gênese do modo institucional de fazer dormir, duas "faces" ou duas finalidades opostas: embalar e conter. A finalidade do embalar carrega consigo uma afetividade, um carinho, um toque no corpo do outro para que relaxe e consiga dormir. Além do que, essa forma de fazer dormir lança mão de uma proxêmica ${ }^{12}$ comum entre as crianças, ou seja, uma distância íntima de aproximação. Por outro lado, a finalidade do conter, nesse modo de fazer dormir, torna evidente um desejo de instituir uma ordem disciplinar e um controle da dimensão corporal das crianças. Contribuem com essa ideia a determinação e o encaminhamento de quais crianças seriam contidas/embaladas primeiramente. Sendo definidor nessa escolha a seleção das crianças que menos se dispunham a ficar deitadas e as definidas como as mais "agitadoras" do grupo. Do mesmo modo, o fato de que enquanto a professora e a auxiliar continham/embalavam duas crianças de cada vez, implicava numa ordem em que as demais crianças deveriam permanecer deitadas e quietas até adormecerem. Para isso, os adultos utilizavam como recurso a seguinte afirmação: "Quem não deitar e ficar quietinho eu vou embalar" 13. Essa afirmação ratifica que, pela via da ordem institucional adulta, o conter/embalar para dormir é concebido como uma forma de conter as crianças. 
$\mathrm{Na}$ rotina do sono, estabelecida pela ordem institucional adulta, os adultos compartilham com as crianças a centralidade do corpo aliado à afetividade, ao toque do corpo e dessa proxêmica íntima. Diferenciando-se da distância social assumida na maioria dos momentos de condução da rotina diária, sobretudo dos momentos de atividade pedagógica e roda. Considerando os limites desse artigo não há possibilidade de aprofundar essa temática, mas no conjunto da tese, ${ }^{14}$ que ora serve de base para este artigo, observou-se que as crianças assumem na maioria de suas relações essa distância íntima ou pessoal, enquanto os adultos assumem mais frequentemente uma distância social das crianças. Esses modos diferenciados de manter distâncias sociais, segundo Hall (1977, 1994), são definidos inconscientemente pelas pessoas como uma distância que seja apropriada para diferentes relacionamentos. As pessoas estabelecem também uma distância confortável para a interação pessoal e definem não verbalmente essa distância como seu espaço pessoal.

As crianças, com suas ações e desejos, parecem apontar para os próprios atos do corpo e não apenas para os atos sobre o corpo, que Ferreira (2009, p. 4) define como necessidade de

[...] redirecionar a análise sociológica no sentido da recuperação fenomenológica e quotidiana das experiências vividas por um corpo que existe de fato, nas suas propriedades, potencialidades e limitações concretas em determinadas práticas e usos do mesmo, referenciáveis não apenas a modos de acção no corpo, mas também a modos de ação do corpo.

Talvez resida aqui o grande interesse das crianças por essa prática do "fazer dormir", interesse que as leva a revisitar essa ação nas brincadeiras entre pares, pois é preciso conceber que, para elas “[...] o corpo está na base de toda a experiência social, enquanto mediadora das relações, das práticas, dos discursos, das apropriações do outro e do mundo [...]" (FERREIRA, 2009, p. 6). Além de observar a repetição desse modo de embalar, nas brincadeiras vividas pelas crianças nos tempos do brincar foi possível observar que algumas crianças passaram, também, a se embalar, dando palmadinhas em seus amigos na hora de dormir, como é possível acompanhar nas fotos a seguir: 


\section{Foto 8}

Bibi embala Manu.

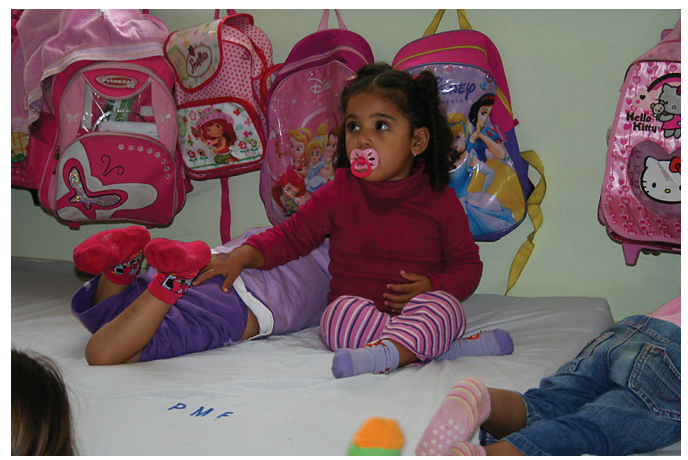

Fonte: da autora, em 23/6/2009.

\section{Foto 9}

Larissa embala Helena.

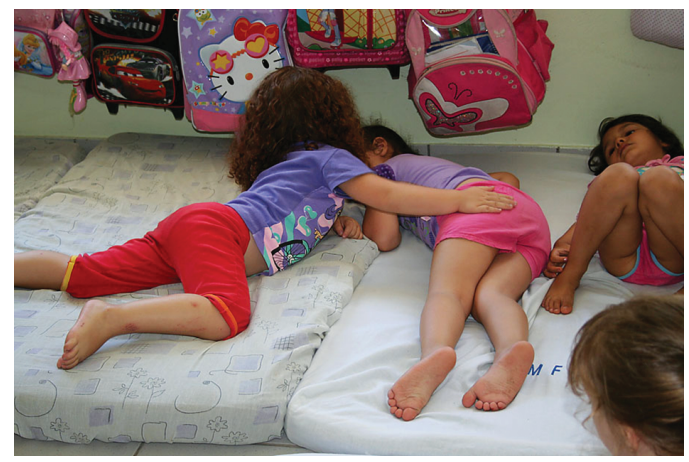

Fonte: da autora, em 10/11/2009.

Quando se observa, nas fotos apresentadas, a ação das crianças se embalando não somente em seus tempos do brincar, mas também nos próprios tempos do sono, ou seja, nos tempos instituídos, definidos e regidos pelos adultos, os quais implicam numa relação formal com as crianças em que os adultos têm um papel central e ativo, é possível compreender que esses ajustamentos secundários são também capazes de gerar, entre elas, um conjunto de saberes e fazeres que as envolve em ações cooperativas na busca de seus interesses. Como também é possível afirmar que, por meio dos ajustamentos secundários, as crianças têm possibilidades reais de gerarem atividades ou organizações novas e qualitativamente diferentes, como também atividades e organizações iguais ou muito semelhantes, mas 
percebidas por elas como distintas, pois fazem parte de sua estruturação como um grupo, com dada cultura, que procura se afirmar perante os enquadramentos primários definidos por uma ordem institucional adulta.

No entanto, essa atividade das crianças pareceu-me durante os sete primeiros meses em campo como uma integração à ordem institucional adulta, pois, constantemente, observava entre as crianças o que analisei como uma mera reprodução das ações dos adultos, tanto nas suas brincadeiras entre pares como nos momentos da rotina do dormir. Aqui compreendo o termo reprodução com base em Corsaro (2002, 2005, 2009), no qual está presente a ideia de que por um lado as crianças são constrangidas e afetadas pelas estruturas sociais e pelas culturas já existentes, ou seja, pela reprodução social nas sociedades das quais participam. Desse modo, pela participação efetiva as crianças também contribuem recíproca e ativamente para a produção e mudança social e cultural do mundo adulto. Todavia, em início de setembro, no horário do sono das crianças percebo um elemento que julgo ser, qualitativamente, diferente:

As crianças já estão todas deitadas nos colchões, a auxiliar acalma Willian e Letícia - dando palmadinhas no bumbum. Amanda chama-me e pede:

Amanda: me faz dormir?

Márcia: é? Como é fazer dormir? [acompanhando esses meses de brincadeiras de "faz̧er dormir" entre as crianças já suspeitava do que se tratava seu pedido, mas queria me certificar].

Amanda se vira um pouco de lado e bate com uma de suas mãos em seu bumbum. Assim me certifico de que ela quer que eu a embale dando palmadinhas. Nesse momento Jennyfer e Iza também me pedem para embalá-las. Fico de joelhos nos colchões para dar conta de embalar as três meninas ao mesmo tempo.

A auxiliar, ao ouvir o pedido da Amanda para que eu a embalasse, sendo que com esse pedido foi possivel evidenciar que ela gostava de ser embalada - pedido que logo é solicitado também por Jennyfer e Isadora -, aproveita para utilizar agora a estratégia: Léo, se você não deitar no colchão eu não vou te embalar.

Eu embalo Amanda, Isadora e Jennyfer por um curto periodo de tempo e depois me despeco de todas as crianças com um beijo (Registro Notas de Campo do dia 1/9/2009).

Quando Amanda solicita que eu, um adulto, a faça dormir, ela lança mão de um ajustamento secundário, pois, até o momento nas cenas presenciadas entre as crianças, o fazer dormir era realizado por/ entre elas nas brincadeiras, já nas horas do sono eram protagonizadas pelos 
adultos - profissionais da instituição - ao fazerem as crianças dormir. No entanto, em ambas as situações não se observa uma solicitação das crianças para serem embaladas, mantendo aquelas duas "faces": controlar e embalar. Avalio a solicitação da Amanda para que eu a embale como um elemento qualitativamente diferente, pois evidencia que, com essa ação, ela potencializa a "face" do embalar como carinho, afetividade e contato corporal e, por outro lado, enfraquece ou elimina a "face" do controle presente na intenção dos adultos ao utilizar essa estratégia para fazer as crianças dormirem, bem como nas brincadeiras observadas entre elas. Aqui cabe relacionar o conceito de reprodução interpretativa cunhado por Corsaro (2002, 2005, 2009), pois este conceito institui um nexo entre o mundo adulto e o mundo infantil, em que as crianças reproduzem interpretativamente o mundo adulto. Nesse nexo o termo interpretativo procura dar relevo aos aspectos inovadores, criativos e transformadores das perspectivas e participações das crianças nas relações sociais. Também salienta apropriações seletivas, reflexivas e críticas que as crianças são capazes de fazer do mundo adulto quando, em um processo de interpretação, o fazem de acordo com seus interesses, necessidades e preocupações como crianças.

Como já mencionei anteriormente, trazer essas cenas do cotidiano observado em uma instituição de educação infantil objetiva vislumbrar como as crianças, ao se confrontarem com a organização dos espaçostempos institucionais adultos, fazem uso desse tempo e desse espaço e como os transformam. Percebe-se que, por um lado, as crianças aderem à organização dos espaços e tempos pensados e efetivados pela professora e pelas auxiliares. Com isso, elas aderem também a uma ordem institucional adulta, contribuindo com sua integração por meio dos ajustamentos primários. Por outro lado, quando as crianças empregam ou conseguem fins não autorizados, ou até ilícitos para escapar daquilo que a organização supõe que elas devem fazer, lançam mão do que Goffman (1961) define como ajustamentos secundários.

Parece ser definidor na aquisição e manutenção desses ajustamentos secundários o fato de outras crianças aderirem ao pedido da Amanda, ou talvez seja possível afirmar que as crianças aqui reproduzem a ação social da iniciativa da Amanda, pois, assim que Amanda solicita que eu a embale - cenas observadas pelos demais adultos -, Isadora e Jennyfer também solicitam que eu as embale. Importa destacar que o pedido de Amanda ganha força, com a adesão, ou dito de outra forma, com a reprodução da ação social pela 
Isadora e Jennyfer. Essa adesão, por outro lado, enfraquece o controle da ordem institucional adulta que passa a não ter mais sentido, e sobretudo a frase que era repetida constantemente de que as crianças seriam embaladas caso não permanecessem deitadas passa a ser obsoleta.

No entanto, para que a ordem institucional adulta seja mantida a estratégia utilizada pelos adultos é mudar o discurso com relação ao processo do conter/embalar as crianças na hora do sono. Ou seja, o adulto, estrategicamente, modifica seu discurso que consistia em: "quem não deitar e ficar quietinho eu vou embalar" o qual já estava instituído pelo ajustamento primário e, numa tentativa de readequação, passa a utilizar: "Léo, se você não deitar no colchão eu não vou te embalar" 15 . Tal mudança indica uma tentativa na busca em manter o controle perdido por meio do ajustamento secundário inaugurado pelas crianças.

Essa mudança no discurso da ordem institucional adulta aponta que, apesar das limitações impostas, as crianças, a partir de suas ações, conseguem também modificar, transformar e transcender elementos já preestabelecidos na cultura dos adultos, por meio de ajustamentos secundários, pois estes "[...] representam formas pelas quais o indivíduo se isola do papel e do eu que a instituição admite para ele" (GOFFMAN, 1961, p. 160). Por meio da rotina instituída do conter/embalar as crianças para dormir, os adultos esperam que elas passem a aderir à ordem institucional adulta, em um processo de integração, e que passem a contribuir com sua manutenção. No entanto, as crianças apontam possibilidades reais de gerarem atividades ou organizações novas e, qualitativamente diferentes, na busca por se afirmarem perante os enquadramentos primários definidos pela ordem institucional adulta.

Perante essa ação social das crianças, os adultos precisam retomar o controle e, para isso, utilizam estratégias as quais revelam que

[...] as organizações têm uma tendência para adaptar-se aos ajustamentos secundários, não apenas através da disciplina cada vez maior, mas também por legitimar seletivamente tais práticas, esperando, dessa forma, reconquistar o controle e a soberania [...]" (GOFFMAN, 1961, p. 165).

Por isso, tendo em conta que as instituições revelam suas fragilidades por meio dos ajustamentos secundários, elas podem também, para manter o controle e a soberania, legitimar, seletivamente, algumas dessas práticas, sobretudo as mais visíveis, ou aquelas que mais se desenvolveram. Esse 
legitimar seletivamente aponta que, afinal, os adultos, apesar das limitações que impõem, também não são totalmente inflexíveis ou irredutíveis face às contribuições que as crianças indicam. Com isso, um ajustamento secundário pode tornar-se um ajustamento primário legitimado institucionalmente.

\section{CONSIDERACְÕES FINAIS}

Ao longo desse texto, ao analisar alguns elementos da organização espaço-temporal, pensada e legitimada pelos adultos, bem como ao analisar o momento do sono, revela que, por um lado, as crianças vão se apropriando dessa ordem institucional adulta e a reproduzindo junto com seus pares. Por outro lado, revela também que as crianças fazem uso seletivo desses conhecimentos, criando e incluindo elementos qualitativamente diferentes, dando emergência, portanto, a uma ordem instituinte das crianças. Revela ainda que por meio das relações sociais as crianças, bem como os adultos, vão produzindo significados sociais e culturais.

Por meio dos vários ajustamentos secundários evidenciados na organização dos espaços, sobretudo no denominado tempo das crianças, mas também na rotina do sono, efetivada no tempo dos adultos, é possível salientar que as crianças são exímias em trabalhar o sistema (GOFFMAN, 1961). O que significa reconhecer que elas têm um profundo conhecimento do seu funcionamento, como destaca Giddens (2000, p. 46) “[...] as instituições não funcionam apenas 'por detrás' dos atores sociais que as produzem e reproduzem. Todo membro competente de qualquer instituição sabe bastante sobre as instituições". É com base nessa capacidade das crianças de ao mesmo tempo reproduzir, mas também produzir e inserir elementos, qualitativamente diferentes, no mundo adulto, que se entende que a ordem institucional, ao mesmo tempo em que constrange as atividades das crianças, também fornece bases para a introdução de elementos qualitativamente diferentes. Como define Giddens (2000, p. 44), “[...] a estrutura não deve ser concebida como uma barreira para a ação, mas sim como encontrando-se envolvida na sua produção". Assim, uma breve incursão nos espaços-tempos institucionais revela indícios do repertório de competências sociais, relacionais, práticas, corporais e discursivas que 
as crianças são capazes de mobilizar ao se confrontarem com uma ordem institucional adulta, como também com seus pares.

Revela também, assim como destaca Dubet (1994, p. 137), que as crianças percorrem um espaço de lógicas de ação em circulação, ou seja, "tudo ao mesmo tempo", compondo arranjos ou produtos das experiências sociais. Por meio dos dados trazidos para análise é possível identificar uma combinação de ações, em que, ao mesmo tempo, as crianças agem num sentido das lógicas de integração aderindo à ordem institucional adulta, quando, por exemplo, permanecem deitadas para dormir e quando "reproduzem" a ação de conter/embalar seus amigos nas brincadeiras ou na própria hora do sono. Ao mesmo tempo, em outras situações as crianças agem num sentido das lógicas estratégicas, apontando para interesses que entram em conflito com essa ordem institucional, a exemplo de quando, estrategicamente, aproveitam a ausência dos adultos, no momento da higiene, para usar os espaços dos colchões para realizar coisas que gostam de fazer. E ainda, em outras situações, agem num sentido de subjetivação compondo uma lógica de ação que traz elementos qualitativamente diferentes à ordem institucional adulta, a exemplo de quando atribuem um outro sentido à ação do conter/embalar instituído pela ordem institucional adulta.

Ao realizar uma análise que permitisse problematizar questões articuladas com ações e práticas educativas, especialmente no que se refere às questões que envolvam as relações sociais das crianças no momento do sono, uma expectativa é que, à medida que o estudo descreve e analisa situações e relações estabelecidas entre as crianças e os adultos, possa contribuir, no sentido de sugerir indicações para a ação docente numa busca pela consolidação de uma Pedagogia da Infância. A partir da perspectiva de uma Pedagogia da Infância, se concebe essencial tirar as crianças da posição periférica, ou da posição de subalternidade frente às discussões pedagógicas que lhes dizem respeito. Da mesma forma, nessa perspectiva, se concebe fundamental as crianças participarem ativamente dos contextos educativos, o qual envolve questionar os ajustamentos primários, o que desafia os adultos, e neste caso o professor de educação infantil, a estabelecer uma aproximação aos universos infantis, exige uma consciência profissional de valorização das práticas educativas. A concretude e a qualificação desses modos de fazer pedagogia só são possíveis de alcançar pelo exercício da observação, do planejamento, do registro, da discussão e da reflexão, em que 
se "olham" não apenas os processos de desenvolvimento das crianças, mas também os seus conhecimentos, as suas produções, as suas manifestações, as suas preferências, as suas interações etc. Tais elementos possibilitam o enfrentamento da imprevisibilidade, que torna a educação infantil singular. Pois precisa estar atenta para perceber e qualificar as interações entre pares, os arranjos, as organizações e a exploração dos espaços e dos tempos, as relações construídas nas brincadeiras, as representações e significações que são manifestadas no choro, no silêncio, no balbucio, na fala, nos gestos, nos olhares, nos movimentos etc. Para tanto, é preciso que o adulto aprenda o exercício da escuta e do olhar atento com intuito de compreender as crianças e as relações que elas estabelecem nas suas particularidades. Não se trata de um olhar qualquer, mas de um olhar e de uma escuta interessada e interrogativa dos modos de ser e viver constitutivos dos mundos infantis. Nesse sentido, o exercício da interrogação toma o lugar das respostas prontas sobre as vidas das crianças. 


\section{REFERÊNCIAS}

BATISTA, R. A rotina no dia-a-dia da creche: entre o proposto e o vivido. 1998. 176 f. Dissertação (Mestrado em Educação)-Universidade Federal de Santa Catarina, Florianópolis, 1998. BUSS-SIMÃO, M. Relações sociais em um contexto de educação infantil: um olhar sobre a dimensão corporal na perspectiva de crianças pequenas. 2012. 312 f. Tese (Doutorado em Educação)-Universidade Federal de Santa Catarina, Florianópolis, 2012.

CORSARO, W. A reprodução interpretativa no brincar ao "faz-de-conta" das crianças. Educação, Sociedade \& Culturas, Porto, n. 17, p. 113-134, 2002.

CORSARO, W. Collective Action and Agency in Young Children's Peer Cultures. In: QVORTRUP, J. (Ed.) Studies in Modern Childhood: Society, agency, culture. Basingstoke: Palgrave Macmillan, 2005. p. 231-247.

CORSARO, W. A. Reprodução interpretativa e cultura de pares. In: MÜLLER, F.; CARVALHO A. M. A. (Orgs.). Teoria e prática na pesquisa com crianças: diálogos com Willian Corsaro. São Paulo: Ed. Cortez, 2009. p. 31-50.

DANBY, S. The serious and playful work of gender: talk and social order in a preschool classroom. In: YELLAND, N. Gender in early childhood. 2nd ed. London and New York: Routledge, 2005. p. 175-205.

DUBET, F. Sociologia da experiência. Lisboa: Instituto Piaget,1994.

FERREIRA, M. M. M. "A gente aqui o que gosta mais é de brincar com os outros meninos!": as crianças como atores sociais e a (re) organização social do grupo de pares no cotidiano de um Jardim de Infância. 2002. 646 f. Tese (Doutorado em Ciências da Educação)-Faculdade de Psicologia e Ciências da Educação, Universidade do Porto, Porto 2002.

FERREIRA, M. Do "avesso" do brincar ou... as relações entre pares, as rotinas da cultura infantil e a construção da(s) ordem(ens) social(ais) instituintes(s) das crianças no Jardimde-Infância. In: SARMENTO, M. J.; CERISARA, A. B. Crianças e Miúdos: perspectivas sociopedagógicas da infância e educação. Porto: Edições ASA, 2004. p. 55-104.

FERREIRA, V. Elogio (sociológico) à carne: A partir da reedição do texto "as técnicas do corpo" de Marcel Mauss. Porto: Instituto de Sociologia, 2009. p. 8. Conferência no lançamento da Colecção Arte e Sociedade, do Instituto de Sociologia, na Faculdade de Letras da Fundação Universidade.

GIDDENS, A. Dualidade da estrutura: agencia e estrutura. Porto: Celta. 2000.

GOFFMAN, E. Manicômios, prisões e conventos. São Paulo: Editora Perspectiva, 1961.

GRAUE, M. E.; WALSH, D. Investigação etnográfica com crianças: teorias, métodos e ética. Lisboa: Fundação Calouste Gulbenkian, 2003.

HALL, E. T. A dimensão oculta. Rio de Janeiro: Francisco Alves. 1977.

HALL, E. T. A linguagem silenciosa. Lisboa: Relógia D’água, 1994.

HALLDÉN, G. The metaphors of childhood in a preschool context. In: AUSTRALIAN ASSOCIATION FOR RESEARCH IN EDUCATION - AARE CONFERENCE, 2005,

Sydney. Proceedings... Sydney: AARE, 2005. Disponível em: <http://www.aare.edu.au/05pap/ hal05001.pdf>. Acesso em: 15 set. 2011.

JAMES, A.; PROUT, A. Constructing and Reconstructing Childhood. Lewes: Falmer Press, 1990.

Educação em Revista | Belo Horizonte | v. 29 | n. 01 | p. 151-178| mar. 2013 
KRAMER, S. Autoria e autorização: questões éticas na pesquisa com crianças. Cadernos de Pesquisa, São Paulo, n. 116, p. 41-59, jul. 2002. http://dx.doi.org/10.1590/ S0100-15742002000200003

\section{NOTAS}

${ }^{1} \mathrm{O}$ uso das imagens, tanto de fotos como de vídeos, foi autorizado por escrito pelos pais das crianças envolvidas na pesquisa.

${ }^{2}$ Utilizo a expressão geração de dados e não coleta de dados com base em Graue e Walsh (2003), que sinalizam o fato de que os dados não "andam por aî" esperando que algum investigador os recolha, ao contrário, eles provêm das relações e das interações complexas que o investigador estabelece com o campo investigado.

3 Agradeço ao DAAD a bolsa de doutoramento que possibilitou a estada por um ano e quatro meses na Alemanha para aprofundamento dos estudos e o acesso aos materiais em língua alemã e inglesa. Considerando o respeito ao texto no original e minha limitação na tradução de outras línguas para a língua portuguesa, citarei, ao longo deste artigo, os excertos na língua original sempre em nota de rodapé: "By acknowledging the social orders of children, social orders of adults can also be identified [...]” (DANBY, 2005, p. 177).

${ }^{4}$ A definição pelo uso do conceito ator social e não pelo de agente é decorrente da opção pelo uso do conceito de ação social e não de agency. A opção pelo conceito de ação se dá em razão de uma compreensão inserida no quadro teórico de uma perspectiva interpretativa, embasada, sobretudo, em categorias desenvolvidas por autores que se enquadram nesse contexto, tal como Max Weber, cujo referencial não exclui a relação ação-estrutura, ao contrário, a compreende de forma dual, ou seja, concebe a existência de uma mútua influência e transformação.

${ }^{5}$ Conforme Halldén (2005), na década de 1980 Chris Jenks (1982), Qvortrup Jens (1987) e Alanen Leena (1988) foram os primeiros a introduzir um novo quadro, seguidos por Allison James e Alan Prout como coeditores do livro Construindo e reconstruindo infância (1990). Este novo quadro voltou-se para a perspectiva das crianças e defendendo a necessidade de estudar as crianças em seu próprio direito, em contraposição à ideia de que são apenas indivíduos no caminho para a vida adulta. Seis teses foram formuladas, as quais estabeleceram uma plataforma paradigmática (JAMES; PROUT, 1990). Desde então, têm havido consideráveis pesquisas usando essa abordagem, o que começou como a sociologia da infância é agora um "guarda-chuva" amplo que abrange estudos da infância por pesquisadores das áreas de Sociologia, Psicologia, Educação, Antropologia, Geografia e História.

${ }^{6}$ Em dias de chuva, as crianças permaneciam na sala e podiam realizar atividades livres ou eram levadas até um salão coberto com brinquedos ou, ainda, para a sala de vídeo.

${ }^{7}$ Essas definições são usadas como sinônimo na instituição observada. 
${ }^{8}$ Desde que circunscrito ao tempo definido pela rotina da instituição e efetivado pelos adultos.

${ }^{9}$ Fala da auxiliar do registro de nota de campo de 8/5/2009.

${ }^{10}$ Considerando questões éticas e aspectos de autoria e autorização (KRAMER, 2002), utilizo o primeiro nome das crianças - em algumas situações utilizo o apelido usado entre as próprias crianças nos seus diálogos e relações -, procurando não revelar o sobrenome e omitir o nome da instituição onde a pesquisa ocorreu.

${ }^{11}$ Essa opção se deu em virtude de minha presença, no início da pesquisa, causar maior inquietude no grupo de crianças e no horário do sono minha presença seria desestabilizadora, por isso a decisão de não participar desse momento desde o primeiro dia em campo.

12 Proxêmica é uma distância espacial definida por Hall $(1977,1994)$ como o uso do espaço pessoal num meio social enquanto produto cultural específico. Para Hall (1977), essa distância social entre as pessoas pode ser relacionada com a distância física: a) distância íntima (contato íntimo); b) distância pessoal (45 a $120 \mathrm{~cm}$ ); c) distância social (120 a $360 \mathrm{~cm}$ - distância das relações com desconhecidos); d) distância pública (mais de 360 $\mathrm{cm}$ - comícios, palestras etc).

${ }^{13}$ Fala da auxiliar do registro de nota de campo de 8/5/2009.

${ }^{14}$ Para acesso a essas informações ver: Buss-Simão (2012).

${ }^{15}$ Falas da auxiliar do registro de nota de campo de 8/5/2009 e 1/9/2009, respectivamente.

Recebido: $11 / 05 / 2012$

Aprovado: $17 / 12 / 2012$

Contato: 